удК 340.1

И. А. Минникес

Байкальский государственный университет, г. Иркутск, Российская Федераиия

И. Д. Ягофарова

Уральский институт управления - филиал Российской академии народного хозяйства и государственной службы при Президенте Российской Федерации, г. Екатеринбург, Российская Федерация

\title{
ИМПЕРАТИВНЫЕ ОГРАНИЧЕНИЯ В ПРАВЕ
}

АНнотАция. В современный период исследуемая проблема приобрела особое звучание в контексте идеи установления ограничений в различных сферах деятельности в целях обеспечения безопасности как государства, так и граждан. Анализ действующего российского законодательства свидетельствует об отсутствии единого подхода к понятию термина «ограничения» и выделяется несколько смысловых подходов. В статье рассматриваются проблема интерпретации понятия «ограничение прав и свобод человека», что позволяет выделить несколько основных подходов к понятию «правовое ограничение». Обобщаются имеющиеся точки зрения по этому вопросу. Делается вывод, что в научной литературе и в языке политико-правовой практики и публицистики пока не сложилось единого подхода к пониманию правового ограничения, что лишний раз подтверждает необходимость активизации научных усилий в области изучения природы, содержания, значимости и роли ограничений в праве. Особое внимание уделяется императивным ограничениям, где обязывания и запреты выступают непосредственными способами ограничений.

КЛЮчЕВЫЕ СЛОВА. ОГраничения в праве; правовые ограничения; императивные ограничения; запреты; обязывания.

ИНФОРМАЦИЯ О СТАТЬЕ. Дата поступления 21 ноября 2016 г.; дата принятия к печати 6 декабря 2016 г.; дата онлайн-размещения 31 марта 2017 г.

\section{A. Minnikes \\ Baikal State University, Irkutsk, Russian Federation \\ I. D. Yagofarova of the Russian Federation, Yekaterinburg, Russian Federation}

The Urals Institute of Administration - Branch of the Russian Academy of National Economy and Public Administration under the President

\section{MANDATORY LIMITATION IN LAW}

ABSTRACT. In the modern period the problem under investigation has acquired a special significance in the context of the idea of establishing limitations in various spheres of activities in order to ensure security of both the state and citizens. An analysis of the current Russian legislation testifies the absence of a unified approach to definition of the term «limitation» and highlights several semantic approaches. The article considers the problem of interpreting the concept of «limitation of human rights and freedoms», which allows to identify some basic approaches to the concept «legal limitation». It summarizes the existing viewpoints on this issue. It makes a conclusion that the scientific literature and the language of political and legal practice and journalism have not yet developed a unified approach to understanding the legal limitation, which once again confirms the need of intensifying research efforts in the field of the nature, content, significance and role of limitations in law. A special attention is paid to mandatory limitations where obligations and prohibitions step out as direct means of limitations.

\section{Baikal Research Journal}


KEYWORDS. Limitations in law; legal limitations; mandatory limitations; prohibitions; obligations.

ARTICLE INFO. Received November 21, 2016; accepted December 6, 2016; available online March 31, 2017.

Вопрос об ограничениях в праве, устанавливаемых со стороны властных институтов, и, прежде всего, государственных, всегда был и остается одним из самых актуальных в политико-правовом отношении на протяжении всей человеческой цивилизации. В современный период эта проблема приобрела особое звучание в контексте идеи установления ограничений в различных сферах деятельности в целях обеспечения безопасности как государства, так и граждан. Конечно, последние мировые события ставят вопросы безопасности на первое место, что дает возможность государственным структурам предметно контролировать и ограничивать частную сферу жизни граждан. И динамика этого процесса вполне понятна. Это привело к тому, что в последнее время государственность, в целом, из правовой стала трансформироваться в превентивную. Предотвращение угроз эта та цель, которая должна оправдать все используемые цели и способы борьбы государства с теми элементами, которые предоставляют угрозу. Но предотвратить в современных условиях можно только при постоянном контроле, и наблюдении не только за потенциальными преступниками, но и за всеми гражданами. Таким образом, граница между превентивным государством и государством-надзирателем достаточно зыбкая. Благодаря усилиям специальных подразделений государства, мы в поле напряжения между свободой и безопасностью активно движемся в сторону безопасности, но происходит это, к сожалению, за счет свободы. Все же, несмотря на приоритет национальной безопасности, не стоит также забывать и о том, что безопасность как определенное благо не может конкурировать со свободой, поскольку свобода является первичным и безусловным благом каждого конкретного индивида. Задача государства, при обеспечении безопасности, заключается не в ограничениях частной деятельности граждан или различных сфер общественно-правовых отношений, а в его ответственности за защиту населения и государства в целом.

Но с другой стороны, также следует учитывать и тот факт, что оптимального баланса интересов государства, общества и личности возможно достигнуть только при ограничении и самоограничении определенных возможностей перечисленными субъектами. Чаще всего на всех уровнях звучит положение о том, что государство не должно вмешиваться в частную жизнь субъектов, что является верным утверждением, но не стоит забывать, что в исключительных случая для обеспечения безопасности самих этих субъектов государство вынуждено применить ограничительные меры, что обосновано целями и способами ограничений. Установление границ является необходимым элементом регулирования общественных отношений, смысл же заключатся в способах, которые при этом используются и императивность их установления.

Понятие «ограничение» имеет как практическое значение, так и теоретическое. И в той, и в другой сфере нет единообразия в понимании. Если говорить о понимании этого понятия в сфере практической деятельности, то это связано с тем, что различного рода ограничения используются в различных сферах правового регулирования, которое имеет и гражданско-правовую, и административно-правовую, и уголовно-правовую направленность. Соответственно, степень императивности этих ограничений напрямую зависит от сферы регулирования. Поскольку практическое закрепление смысла и содержания «ограничения» более конкретно, то начнем анализ с этой сферы.

\section{Baikal Research Journal}

электронный научный журнал Байкальского государственного университета 
Если говорить о понятии «ограничение», используемого в законодательстве России, то возможно выделить несколько смысловых значений, в котором оно используется [1, с. 443]:

- ограничение может трактоваться как «полная или частичная утрата лицом способности или возможности осуществлять самообслуживание, самостоятельно передвигаться, ориентироваться, общаться, контролировать свое поведение, обучаться и заниматься трудовой деятельностью» (ст. 1 Федерального закона «О социальной защите инвалидов в Российской Федерации» от 24 ноября 1995 г. № 181-Ф3);

- в сфере уголовного законодательства ограничение понимается как «содержание осужденного, достигшего к моменту вынесения судом приговора восемнадцатилетнего возраста, в специальном учреждении без изоляции от общества в условиях осуществления за ним надзора» (ст. 53 Уголовного кодекса РФ);

- ограничения как наличие установленных законом или уполномоченными органами в предусмотренном законом порядке условий, запрещений, стесняющих правообладателя при осуществлении права собственности либо иных вещных прав на конкретный объект недвижимого имущества (сервитута, ипотеки, доверительного управления, аренды, ареста имущества и других) (ст. 1 Федерального закона «O государственной регистрации прав на недвижимое имущество и сделок с ними» от 21 июля 1997 года № 122-Ф3);

- также под ограничением могут пониматься различные административные, медико-санитарные, ветеринарные и иные мер, направленные на предотвращение распространения инфекционных заболеваний и предусматривающие особый режим хозяйственной и иной деятельности, ограничение передвижения населения, транспортных средств, грузов, товаров и животных (ст. 1 и 31 Федерального закона «О санитарно-эпидемиологическом благополучии населения» от 30 марта 1999 г. № 52-Ф3).

Но в данном случае ограничения рассматриваются более предметно и узко, с точки зрения правоприменительной практики, что является вполне логичным и понятным с позиции реального воплощения в различных сферах практической реализации. Если же рассматривать общее понимание понятие «ограничение», то в энциклопедических и толковых словарях оно преимущественно трактуется как «стеснение какими-то условиями; лимитирование сферы деятельности, сужение возможностей и т. п.» [2, с. $320 ; 3$, с. 357].

Юридическая наука характеризуется отсутствие унифицированного понимания определенных категорий, что представляет собой определенную сложность, но в то же время, дает больше возможностей для практического применения. Понятие «ограничение» не является исключением. Авторы имеют различные позиции по данному вопросу, что обусловлено разновекторностью наполнения этого понятия. Проведенный анализ позиций авторов, позволяет выделить несколько ведущих подходов к пониманию «ограничения» в сфере прав и свобод человека. Анализ позиций авторов по вопросу интерпретации «ограничения прав и свобод человека» позволяет выделить несколько ведущих подходов к трактовке понятия правового ограничения.

1. Согласно мнению авторов, ограничение можно понимать как особую совокупность мер системного характера, которые представляют собой определенную трудность или препятствие для реализации субъектами права их прав и свобод. В то же время эти меры направлены на обеспечение оптимального баланса интересов общества, государства и личности $[4$, с. 10] . Однако «трудность» или «препятствие» в большей мере понимаются как сложности, создаваемые неправомерным путем со стороны различных органов и влекущие определенные для последствия,

\section{Baikal Research Journal}


но не те меры, которые могут создаваться государством и представлять собой определенные трудности для реализации субъектами своих прав, что не соответствует сущности самого государства и права в целом.

2. Согласно следующей позиции, ограничение понимается как некое уменьшение объема прав и свобод субъектов. Подобное положение является наиболее вероятностным, поскольку в этом случае сохраняется само право и возможность его использования, однако уменьшается его объем и варианты реализации. А. А. Кондрашов отмечает, что ограничением следует называть сокращение правомочий, и установление дополнительных правовых условий для реализации тех или иных правомочий (правопритязаний), а также форм и способов защиты права от нарушений [5]. Именно такое понимание дает возможность избежать злоупотребления со стороны законодателей при установлении ограничений, поскольку предусматривается сохранение самого права и возможности его реализации в целом.

3. Некоторые исследователи понимают ограничение как либо полное изъятие права, либо его определенной части. Как указывает Б. С. Эбзеев, «в качестве ограничения основных прав может рассматриваться также изъятие из круга правомочий, составляющих нормативное содержание основных прав и свобод» [6, с. 24]. Н. С. Малютин также под ограничением понимает «специфическую модификацию права, связанную с “изъятием” отдельной составляющей полномочия, точнее - с исключением определенной возможности правопользования в целях/интересах, лежащих вне конституционного правопорядка и сущности самого права» [7]. Хотя, при таком понимании, скорее, уже происходит не ограничение права, а его либо полное лишение, либо его части, что в любом случае не является тождественным.

4. Другие авторы соотносят ограничение с понятием равенства (М. Н. Козюк $[6$, с. 52]). Их позиция строится на том, что в праве закрепляется как равенство субъектов, так и их неравенство, которое выражается в том, что ряду субъектов предоставляются различные льготы, иммунитеты, привилегии и т. д. [8; 9]. Более того, и само равенство имеет относительный характер. Но данном случае речь может идти лишь о формальном равенстве, поскольку изначально субъекты также появляются с разным набором физических и умственных данных, что предопределяет их неравный характер. Именно в связи с этим чаще всего и пытается государство восстановить справедливость, путем предоставления различного льгот и привилегий, пытаясь обеспечить хотя бы формальный принцип равенства. Конечно, следует учитывать и злоупотребления различными привилегиями и льготами определенными категориями лиц, однако, это проблема иной сферы правового регулирования. В рамках этого же подхода возможно отметить, что ряд авторов рассматривают ограничения как пределы реализации субъектами своих прав, выражающиеся в запретах, вторжениях, обязанностях, ответственности [10, с. $6 ; 11$, с. 12$]$.

5. Заключительный подход рассматривает ограничения как изменение содержания прав и свобод человека [12, с. 62]. Авторы выделяют широкое понимание ограничения, которое в данном смысле понимается как родовое понятие и узкое понимание, которое заключается в трактовке ограничения как особой формы опосредования основных прав субъекта. Вот именно узкое понимание ограничения позволяет говорить об изменении содержания прав субъекта, но которое, при этом, не должно затрагивать саму сущность права. По мнению авторов, ограничение является объективно неизбежным условием существования государственности, позволяющее конституционным способом уточнять правила и условия пользования субъектами своими правами и свободами [13, с. 29].

Представленные взгляды исследователей еще раз позволяют заключить, что в научной литературе и юридической практике нет унифицированного подхода к

\section{Baikal Research Journal}

электронный научный журнал Байкальского государственного университета 
пониманию правового ограничения, что подтверждает необходимость и целесообразность исследований природы, содержания и значимости ограничений в праве. Единообразное понимание правового ограничения позволило бы привести в соответствие теоретические позиции, что напрямую бы повлияло на практическую сторону деятельности.

Анализ вышеизложенного дает возможность вполне основательно говорить о том, что всякое ограничение предполагает императивный характер, поскольку оно исходит от государства в виде властного веления и государство располагает различными принудительными мерами за неисполнение этих предписаний. Императивность является неотъемлемым качеством права, которое представляет собой комплекс категорических предписаний, которые фиксируются в праве и отражают его общеобязательность и требовательность в регулировании общественных отношений. Прежде всего, императивность отражается в методе правового регулирования, а также в нормах права и предполагает отсутствие возможности отклонения от имеющихся предписаний, что является вполне логичным и обоснованным. Таким образом, императивность придает ограничениям особый характер и роль в правовом регулировании сложившихся отношений.

Императивность ограничений проявляется также и в способах их установления, что является неотъемлемым элементом правового регулирования. $\mathrm{K}$ таким способам возможно отнести обязывание и запрет, которые, в отличии от дозволения, так или иначе предусматривают некое уменьшение вариантов действия. Суть обязывания заключается в возложении на субъекта обязанности совершить какие-либо активные действия [14, с. 544; 15, с. 343]. Рассматривая сущность обязывания, С. С. Алексеев отмечал, что «позитивные обязывания... все же в большей мере связаны с принуждением, а не со стимулированием поведения людей» [16, с. 269]. Действительно, любое обязывание устанавливается в интересах управомоченного лица, что, соответственно, предполагает осознание, как отмечал Г. Ф. Шерешеневич, «связанность своей воли. Человек вынужден сообразовывать свое поведение с предъявленными к нему извне требованиями.... Человек действует не так, как побуждают его собственные интересы, он считает необходимым ограничить себя в возможном фактически осуществлении интересов из-за интересов других» $[17$, с. 210$]$.

Предоставляя субъекту право, государство, тем самым, предоставляет ему также возможность действовать согласно свое воле и желанию, направляя свои усилия на реализацию этого права либо отказ от его использования. В отношении же обязанности такого свободного выбора не происходит и у субъекта нет воли выбирать вариант или модель поведения. Они для четко прописаны в законодательстве и исключают (как правило) другие варианты поведения. Тем самым путем обзывания происходит ограничение возможности выбора модели поведения. В качество примера можно привести правила регистрации религиозных организаций, которые предусматривают определенные сроки данной регистрации, в пределах которых религиозная организация должна предоставить информацию в компетентные органы об изменении своей организационной формы, наименования, адреса и т. п. (Федеральный закон «О свободе совести и о религиозных объединениях» от 26 сентября 1997 г. № 125-ФЗ). Данное положение представляет собой обязанность, которую установил законодатель для данного вида организаций, при невыполнении которой указываются также и возможные последствия.

Если субъект не выполняет возложенную обязанность, то происходит разрушение всей конструкции взаимосвязанных общественных отношений и управомоченный субъект, в свою очередь. Не может в полной мере реализовать свое право. Поэтому, как совершенно справедливо подчеркивает А. В. Малько, обязанность

\section{Baikal Research Journal}

электронный научный журнал Байкальского государственного университета 
является обратной стороной субъективного права и выступает именно ограничением, а не стимулом [18, с. 100$]$.

Запрет представляет собой разновидность обязанности, которая предполагает необходимость воздерживаться от совершения какого-либо действия, казанного в юридической норме. В. С. Нерсесянц указывал, что «в праве запреты носят исходный, фундаментальный характер и выражают самую суть права и правовой регуляции, состоящую в том, чтобы исчерпывающе, четко и прямо запретить все негативное (общественно вредное в действиях и отношениях людей) и таким путем признать и взять под свою защиту все остальное в качестве положительного, общественно не вредного» [19, с. 91]. Разумеется, что запреты могут рассматриваться и с положительной стороны, поскольку они действительно направлены на защиту интересов и прав самих субъектов, а также государств и общества. Данный способ регулирования является одним из древнейших и показал свою высокую эффективность и надежность. По мнению С. С. Алексеева, запреты - это необходимые, важные юридические средства обеспечения организованности общественных отношений, охраны прав и законных интересов граждан, общественных объединений, всего общества, создания барьера для нежелательного, социально вредного поведения. Во многих случаях запрещения представляют собой переведенные на юридический язык и оснащенные юридической санкцией моральные запреты [20, с. 355-356]. Негативной стороной запретов является жесткое ограничение поведения субъектов путем установления пределов такого поведения или его полного запрета и в то же время ограничиваются возможности вмешательства государства в сферу субъективных прав и свобод [21, с. 6].

Если сравнивать обязывания и запрет как способы правового регулирования с точки зрения эффективности, то запрету отдается приоритет «не по количественным показателям, чем больше запретов тем, лучше, а по воздействующим на общественные отношения свойствам запрета» [22, с. 351-353]. С этим мнением стоит согласиться, поскольку ограничительное воздействие права на субъектов в конституционно установленных целях наиболее целесообразно и действенно устанавливать запретительным путем, поскольку субъектам необходимо видеть и знать границы дозволенного и запрещенного для результативного участия в общественных отношениях. Если запрет является способом ограничения, то само ограничение представляет собой уже результат применения этого способа. К примеру, в ст. 16 Федерального закона «Об общественных объединениях» от 19 мая 1995 г. № 82-Ф3 устанавливается запрет на создание и деятельность общественных организаций, цели которых направлены на осуществление экстремистской деятельности. Как можно видеть, вне зоны охвата данным запретом (ограничения) остаются общественные организации, которые не ставят в своих уставных документах указанных антиобщественных целей.

Тема императивности ограничений в праве представляет собой объемный неразработанный пласт, освоение которое позволит обозначить и выявить наиболее эффективное способы придания властного характера нормативным предписаниям, не нарушая, в то же время, зыбкого баланса частно-правовых и публичных интересов.

\section{Список использованной литературы}

1. Словарь-справочник по российскому законодательству / под ред. Л. Ф. Апт. - М. : Юристь, 2001. - 910 с.

2. Лопатин В. В. Малый толковый словарь русского языка / В. В. Лопатин. - 2-е изд., стер. - М. : Рус. яз., 1993. - 704 с.

3. Ожегов С. И. Словарь русского языка : ок. 57000 слов / С. И. Ожегов ; под ред. Н. Ю. Шведовой. - 18-е изд., стер. - М. : Рус. яз., 1988. - 797 с.

\section{Baikal Research Journal}

электронный научный журнал Байкальского государственного университета 
4. Москаленко Т. О. Конституционно-правовые основания ограничения прав и свобод человека и гражданина в целях обеспечения безопасности Российской Федерации : автореф. дис. ... канд. юрид. наук : 12.00 .01 / Т. О. Москаленко. - М., 2012. - 23 с.

5. Кондрашев А. А. Ограничения конституционных прав в Российской Федерации: теоретические подходы и политико-правовая практика / А. А. Кондрашев // Конституционное и муниципальное право. - 2014. - № 7. - С. 40-47.

6. Морозова Л. А. Принципы, пределы, основания ограничения прав и свобод человека по российскому законодательству и международному праву : материалы «круглого стола» / Л. А. Морозова // Государство и право. - 2008. - № 7. - С. 39-70.

7. Малютин Н. С. Роль судебного толкования в разграничении теоретико-правовых конструкций правового регулирования, ограничения и умаления прав и свобод человека и гражданина / Н. С. Малютин // Конституционное и муниципальное право. - 2014. № 3. - С. 20-27.

8. Малько А. В. Стимулы и ограничения в праве (Теоретико-информационный аспект) : автореф. дис. ... д-ра юрид. наук : 12.00.01 / А. В. Малько. - Саратов, 1995. — 40 с.

9. Суменков С. Ю. Привилегии и иммунитеты как общеправовые категории : автореф. дис. ... канд. юрид. наук : 12.00.01 / С. Ю. Суменков. - Саратов, 2002. - 26 с.

10. Квитко А. Ф. Конституционно-правовые основы ограничения прав и свобод человека и гражданина в Российской Федерации : автореф. дис. ... канд. юрид. наук : 12.00.01/ А. Ф. Квитко. - М., 2007. - 24 с.

11. Рассолова Е. Ш. Ограничения прав и свобод человека и гражданина в Российской Федерации: конституционно-правовое исследование : автореф. дис. ... канд. юрид. наук : 12.00.01 / Е. Ш. Рассолова. - М., 2009. - 27 с.

12. Крусс В. И. Выступление на «круглом столе» «Принципы, пределы, основания ограничения прав и свобод человека по российскому законодательству и международному праву» / В. И. Крусс // Государство и право. - 1998. - № 8. - С. 25.

13. Крусс В. И. Теория конституционного правопользования / В. И. Крусс. - М. : Норма, 2007. - 752 с.

14. Теория государства и права : учебник / под ред. В. М. Корельского, В. Д. Перевалова. - 2-е изд., изм. и доп. - М. : Норма: Инфра-М, 2001. - 616 с.

15. Черданцев А. Ф. Теория государства и права : учебник / А. Ф. Черданцев. - М. : Юристь, 2003. - 395 с.

16. Алексеев С. С. Общие дозволения и общие запреты в советском праве / С. С. Алексеев. - М. : Юрид. лит., 1989. - 288 с.

17. Шершеневич Г. Ф. Общая теория права : учеб пособие (по изд. 1910-1912 гг.) : в 2 т. / Г. Ф. Шершеневич. - М. : Изд-во Юрид. колледжа МГУ, 1995.

18. Малько А. В. Стимулы и ограничения в праве / А. В. Малько. - 2-е изд., перераб. и доп. - М. : Юристъ, 2003. - 250 с.

19. Нерсесянц В. С. Философия права / В. С. Нерсесянц. - М. : Норма, 2005. - 656 с.

20. Алексеев С. С. Право: азбука - теория - философия: опыт комплексного исследования / С. С. Алексеев. - М. : Статут, 1999. - 712 с.

21. Султыгов М. М. Запрет как метод правового регулирования : дис. ... канд. юрид. наук : 12.00.01 / М. М. Султыгов. - СПб., 1996. - 150 с.

22. Скрипель В. А. Соотношение дозволения, запрета и позитивного обязывания как способов правового регулирования общественных отношений / В. А. Скрипель // Приоритетные направления развития науки и образования : материалы VII Междунар. науч.-практ. конф. Чебоксары, 4 дек. 2015 г. / О. Н. Широков [и др.]. - Чебоксары : Центр науч. сотрудничества «Интерактив плюс», 2015. - Вып. 4 (7). — С. 351-353.

\section{References}

1. Apt L. F. (ed.). Slovar'-spravochnik po rossiiskomu zakonodatel'stvu [Russian Legislation Dictionary and Handbook]. Moscow, Yurist” Publ., 2001. 910 p.

2. Lopatin V. V. Malyi tolkovyi slovar' russkogo yazyka [Small Definition Dictionary of the Russian Language]. $2^{\text {nd }}$ ed. Moscow, Russkii yazyk Publ., 1993. 704 p.

3. Ozhegov S. I., Shvedova M. Yu. (ed.) Slovar russkogo yazyka [Dictionary of the Russian Language]. 18 ${ }^{\text {th }}$ ed. Moscow, Russkii yazyk Publ., 1988. 797 p.

\section{Baikal Research Journal}


4. Moskalenko T. O. Konstitutsionno-pravovye osnovaniya ogranicheniya prav $i$ svobod cheloveka $i$ grazhdanina $v$ tselyakh obespecheniya bezopasnosti Rossiiskoi Federatsii. Avtoref. Kand. Diss. [Constitutional and legal grounds for limitation of human rights and freedoms in order to provide security of the Russian Federation. Cand. Diss. Thesis]. Moscow, 2012. 23 p.

5. Kondrashev A. A. Limitations of constitutional rights in the Russian Federation: theoretical approaches and political-law practice. Konstitutsionnoe $i$ munitsipalnoe pravo $=$ Constitutional and Municipal Law, 2014, no. 7, pp. 40-47. (In Russian).

6. Morozova L. A. Principles, limits, foundations of limitation of human rights and freedoms in accordance with Russian legislation and international law. Materials of the "round table». Gosudarstvo $i$ pravo $=$ State and Law, 2008, no. 7, pp. 39-70. (In Russian).

7. Malyutin N. S. Role of judicial interpretation in delimitation of theoretical-law constructions of legal regulation, limitations and denial of human and citizen's rights and freedoms. Konstitutsionnoe $i$ munitsipalnoe pravo = Constitutional and Municipal Law, 2014, no. 3, pp. 20-27. (In Russian).

8. Malko A. V. Stimuly i ogranicheniya v prave (Teoretiko-informatsionnyi aspekt). Avtoref. Dokt. Diss. [Stimuli and limitations in law (Theoretical and information aspect). Doct. Diss. Thesis]. Saratov, 1995. 40 p.

9. Sumenkov S. Yu. Privilegii i immunitety kak obshchepravovye kategorii. Avtoref. Kand. Diss. [Privileges and immunities as general legal categories. Cand. Diss. Thesis]. Saratov, 2002. $26 \mathrm{p.}$

10. Kvitko A. F. Konstitutsionno-pravovye osnovy ogranicheniya prav $i$ svobod cheloveka $i$ grazhdanina $v$ Rossiiskoi Federatsii. Avtoref. Kand. Diss. [Constitutional and legal grounds for limiting human and citizen's rights and freedoms in Russian Federation. Cand. Diss. Thesis]. Moscow, 2007. 24 p.

11. Rassolova E. Sh. Ogranicheniya prav i svobod cheloveka i grazhdanina $v$ Rossiiskoi Federatsii: konstitutsionno-pravovoe issledovanie. Avtoref. Kand. Diss. [Limitations of human and citizen's rights and freedoms in Russian Federation: constitutional and legal investigation. Cand. Diss. Thesis]. Moscow, 2009. 27 p.

12. Kruss V. I. Addressing at the «Round Table»: «Principles, margins, grounds for limiting human rights and freedoms according to Russian legislation and international law». Gosudarstvo i pravo = State and Law, 1998, no. 8, p. 25. (In Russian).

13. Kruss V. I. Teoriya konstitutsionnogo pravopol'zovaniya [Theory of constitutional law use]. Moscow, Norma Publ., 2007. 752 p.

14. Korelsky V. M., Perevalov V. D. (eds). Teoriya gosudarstva i prava [Theory of State and Law]. $2^{\text {nd }}$ ed. Moscow, Norma-Infra-M Publ., 2001. 616 p.

15. Cherdantsev A. F. Teoriya gosudarstva i prava [Theory of State and Law]. Moscow, Yurist" Publ., 2003. 395 p.

16. Alekseyev S. S. Obshchie dozvoleniya i obshchie zaprety $v$ sovetskom prave [General permissibilities and general prohibitions in Soviet law]. Moscow, Yuridicheskaya Literature Publ., 1989. 288 p.

17. Shershenevich G. F. Obshchaya teoriya prava [General Theory of Law]. Moscow, Juridical College of MSU Publ., 1995.

18. Malko A. V. Stimuly $i$ ogranicheniya $v$ prave [Stimuli and limitations in law]. $2^{\text {nd }}$ ed. Moscow, Yurist" Publ., 2003. 250 p. $656 \mathrm{p}$.

19. Nersesyants V. S. Filosofiya prava [Philosophy of Law]. Moscow, Norma Publ., 2005.

20. Alekseyev S. S. Pravo: azbuka - teoriya - filosofiya: Opyt kompleksnogo issledovaniya [Law: alphabet - theory - philosophy: Experience of a Comprehensive Study]. Moscow, Statut Publ., 1999. 712 p.

21. Sultygov M. M. Zapret kak metod pravovogo regulirovaniya. Kand. Diss. [Prohibition as a method of legal regulation. Cand. Diss.]. Saint Petersburg, 1996. 150 p.

22. Skripel V. A. Correlation of permissibility, prohibition and positive obligations as means of legal regulation of public relations. Shirokov O. N. et al. (eds). Prioritetnye napravleniya razvitiya nauki i obrazovaniya. Materialy VII Mezhdunarodnoi nauchno-prakticheskoi konferentsii. Cheboksary, 4 dekabrya 2015 g. [Priority Trends of Developing Science and Education. Materials of the $7^{\text {th }}$ International Scientific Conference. Cheboksary, December 4, 2015]. Cheboksary, Center for Scientific Cooperation «Interactive Plus» Publ., 2015, iss. 4 (7), pp. 351-353. (In Russian).

\section{Baikal Research Journal}




\section{Информация об авторах}

Минникес Илья Анисилович - доктор юридических наук, профессор, кафедра теории государства и права и социально-правовых дисциплин, Байкальский государственный университет, 664003, г. Иркутск, ул. Ленина, 11, e-mail: iaminnikes@yandex.ru.

Ягофарова Инара Далировна - кандидат юридических наук, доцент, кафедра теории и истории государства и права, Уральский институт управления - филиал Российской академии народного хозяйства и государственной службы при Президенте Российской Федерации, 620144, г. Екатеринбург, ул. 8 Марта, 66, e-mail: vaina3@yandex.ru.

\section{Author}

Ilya A. Minnikes - Doctor habil. (Law), Professor, Chair of Theory and History of State and Law, Baikal State University, 11 Lenin St., 664003, Irkutsk, Russian Federation; e-mail: iaminnikes@yandex.ru.

Inara D. Yagofarova - PhD in Law, Associate Professor, Chair of Theory and History of State and Law, Urals Institute of Administration, Branch of the Russian Academy of National Economy and Public Administration under the President of the Russian Federation, 66, 8 Marta St., 620144, Yekaterinburg, Russian Federation; e-mail:_vaina3@yandex.ru.

\section{Библиографическое описание статьи}

Минникес И. А. Императивные ограничения в праве / И. А. Минникес, И. Д. Ягофарова // Baikal Research Journal. — 2017. — T. 8, № 1. — DOI: 10.17150/2411-6262.2017.8(1).20.

\section{Reference to article}

Minnikes I. A., Yagofarova I. D. Mandatory restrictions in law. Baikal Research Journal, 2017, vol. 8, no. 1. DOI: 10.17150/2411-6262.2017.8(1).20. (In Russian).

\section{Baikal Research Journal}

